\title{
Should we monitor the direct oral anticoagulants?
}

\author{
Robert Diep $^{1}$ (1) $\cdot$ David Garcia ${ }^{1}$
}

Published online: 23 April 2020

(c) Springer Science+Business Media, LLC, part of Springer Nature 2020

The direct oral anticoagulants (DOACs) are a novel class of drugs that have shifted the paradigm for anticoagulation. DOACs largely obviate the need for laboratory monitoring and are prescribed at pre-specified doses for varying indications including venous thromboembolism (VTE) treatment, VTE prevention, and stroke prophylaxis for non-valvular atrial fibrillation. It is unclear if the current fixed dosing strategy can be improved by measuring DOAC levels in selected populations.

The available DOACs have shown both inter-individual and intra-individual pharmacokinetic variability [1-4]. Even less predictable drug concentrations have been associated with advanced age, renal insufficiency, and body weight extremes [5-7]. All of the approved DOACs are substrates of P-glycoprotein, an important mediator of drug interactions. In addition, both rivaroxaban and apixaban - the two commonly used DOACs - are dependent on the cytochrome P450 enzyme [8]. Thus, concomitant use of medications that, for example, inhibit both the P-glycoprotein and cytochrome $\mathrm{P} 450$ systems could increase the plasma level of a DOAC. Finally, there is uncertainty about whether conditions associated with gastrointestinal malabsorption, such as bariatric surgery, may affect DOAC levels $[9,10]$.

While multiple patient characteristics impact the pharmacodynamics and pharmacokinetics of DOACs, there are no established therapeutic ranges to guide dosing. That notwithstanding, there is growing evidence that monitoring drug levels could be informative, and perhaps clinically actionable. In a prospective study of 565 patients with atrial fibrillation and newly initiated on a DOAC, patients were subdivided into quartiles based on trough levels. Although underpowered with a relatively low number of events, the lowest quartile of drug levels appeared to correlate with a higher risk of thromboembolic events [11]. Secondary

Robert Diep

rdiep@uw.edu

1 Division of Hematology, Department of Medicine, University of Washington, Seattle, WA, USA analysis of the ENGAGE-AF data revealed that increasing edoxaban concentration associated with both a gradual decrease in the risk of stroke or systemic embolic events as well as a steep increase in the risk of major bleeding [12]. Further subgroup analysis also demonstrated an association between higher creatinine clearance, lower trough edoxaban values, and less efficacy to prevent arterial thromboembolism [13]. In the RE-LY trial for patients with atrial fibrillation on dabigatran, plasma concentrations correlated with ischemic stroke and bleeding outcomes, with age being the most important covariate [14]. Likewise, the anti-factor $\mathrm{Xa}$ activity (anti-Xa) has also been evaluated as a surrogate marker for clinically important outcomes. A post hoc analysis of the AVERROES pharmacokinetic substudy displayed a relationship between minor bleeding and anti-factor $\mathrm{Xa}$ activity. Among patients in the lowest decile of anti-Xa activity, a significantly greater risk of stroke was observed compared to those patients with higher anti-Xa activity [15]. In acute stroke patients, one prospective study found early initiation of rivaroxaban or apixaban had the highest likelihood of hemorrhagic complications in patients with high anti-Xa troughs and peaks [16]. In another prospective study, women who experienced mucosal bleeding were found to have higher rivaroxaban doses (per kilogram) and higher anti-Xa levels than non-bleeders [17].

We commend the authors of the three original articles on model-predicted rivaroxaban exposure published in this edition of Journal of Thrombosis and Thrombolysis. In short, the authors performed post hoc exposure-response analyses of data from the landmark trials involving rivaroxaban in the treatment of VTE (EINSTEIN), prevention of VTE (RECORD), and prophylaxis in atrial fibrillation (ROCKET$\mathrm{AF})$. In the absence of measured rivaroxaban drug levels, the authors predicted individual rivaroxaban exposures by relying on prothrombin time (PT) to enhance an established integrated population pharmacokinetic model. These PT measurements were performed in central laboratories with a rivaroxaban-sensitive assay [18]. The overarching consensus from these studies was that the relationship between predicted rivaroxaban exposure and either efficacy or safety was 
quite "shallow," implying a lack of clinical utility for routine rivaroxaban monitoring. However, there were interesting findings in the subgroup analyses that are worth expounding.

In regard to bleeding and safety across these rivaroxaban-related data sets, concentration troughs greater than or equal to the 95th percentile were associated with a higher risk of major or non-major clinical bleeding. Overall, the absolute risk differences were small. But in the interpolation of the ROCKET-AF data, among the subgroup of patients with a history of gastrointestinal bleeding, persons with a trough concentration in the median versus the 95th percentile were predicted to have a $5.1 \%$ versus $6.9 \%$ risk of major bleeding at 1 year. While this difference may or may not be large enough to justify measurement of rivaroxaban levels in patients with a history of gastrointestinal bleeding, confirmation of a relationship between drug exposure and outcomes is a critical step to assess the possible value of drug monitoring.

Nevertheless, other studies have been unable to find nor demonstrate a clear relationship between drug exposure and outcomes. These conflicting results can even be seen in the same exposure analysis of the ROCKET-AF data, in which higher rates of stroke or systemic embolism were observed in the subgroup with prior history of stroke or myocardial infarction, but there was little or no relationship between predicted rivaroxaban concentration and the risk of arterial thromboembolism. In similar modeling methodology, but instead to predict exposure levels of prophylactic apixaban in the setting of orthopedic surgery, 100\% and 200\% increases in apixaban exposure were associated with clinically negligible changes to bleeding frequencies [19]. In the ARISTOTLE trial, apixaban drug concentrations were expectedly lower at the $2.5 \mathrm{mg}$ versus $5 \mathrm{mg}$ twice daily dosing, but the coagulation biomarkers, mortality, and bleeding were consistent across both dosing populations [20]. Across the EINSTEIN and ROCKET-AF data, there was an association between creatinine clearance less than $50 \mathrm{~mL} / \mathrm{min}$ and a higher risk of recurrent VTE or other embolic events. This finding of higher thrombosis (but not bleeding) rates in patients with moderate or severe renal impairment (who, if anything, should have higher drug concentrations) has been seen in other settings [21]; it is an association that highlights the difficulty of confirming or excluding causal relationships between drug exposure and the risk of adverse outcomes.

These interesting model-predicted rivaroxaban exposure studies, although elegant in design, do have limitations. As discussed by the authors, the dearth of actual pharmacokinetic data from these trials, along with the low event rates, preclude definitive conclusions about whether drug exposure might, especially at the extremes, correlate with the risk of adverse outcomes. The predicted exposure model does assume a linear relationship between rivaroxaban and the prolongation of the PT [18], and the degree to which this modeling reflects actual measured rivaroxaban plasma levels is not known. The use of PT prolongation as a surrogate for rivaroxaban drug levels may be problematic because PT can be affected by other processes [22]. While the adjustments for confounding were commendable, it is unlikely that they fully account for the impact of different patient characteristics on outcome rates.

In summary, the work in these predictive models for rivaroxaban exposure support the dogma that generalized, routine DOAC monitoring is unnecessary across various indications. That being said, it is clear that efficacy and safety outcomes are associated with drug level extremes as well as with selected patient characteristics, such as advanced age, body weight extremes, or renal impairment. Indeed, the data from these rivaroxaban exposure-analyses fall short of disproving the hypothesis that very high or very low drug levels might be associated with important increases in bleeding or thrombosis risk. However, even if such a hypothesis were proven correct, no guidance exists as to how a provider would respond to an outlier drug level in a particular patient. One concern would be that, given the significant inter- and intra-patient variability in DOAC levels observed in other studies [1-4], clinicians would not know which values to act upon. For a patient who had consistently very high or very low drug levels, a different anticoagulant may be considered. But could we be certain the risk-benefit tradeoffs would be better after such a switch? In the absence of an evidencebased approach that incorporates laboratory measurements of DOAC effect, clinicians must-especially when treating patients with risk factors for major bleeding (e.g. renal insufficiency, anemia, and concomitant antiplatelet therapy)continue to carefully weigh the risks and benefits of any anticoagulant therapy.

Funding Research reported in this publication was supported by the NHLBI under award number T32HL007093.

\section{Compliance with ethical standards}

Conflict of interest No disclosures or conflicts of interest to report.

\section{References}

1. Mueck W, Schwers S, Stampfuss J (2013) Rivaroxaban and other novel oral anticoagulants: pharmacokinetics in healthy subjects, specific patient populations and relevance of coagulation monitoring. Thromb J 11:10-10. https://doi.org/10.1186/1477-9560-11-10

2. Chan NC, Coppens M, Hirsh J, Ginsberg JS, Weitz JI, Vanassche T, Douketis JD, Schulman S, Eikelboom JW (2015) Real-world variability in dabigatran levels in patients with atrial fibrillation. $\mathrm{J}$ Thromb Haemost 13:353-359. https://doi.org/10.1111/jth.12823 
3. Dimatteo C, D'Andrea G, Vecchione G, Paoletti O, Cappucci F, Tiscia GL, Buono M, Grandone E, Testa S, Margaglione M (2016) Pharmacogenetics of dabigatran etexilate interindividual variability. Thromb Res 144:1-5. https://doi.org/10.1016/j.throm res.2016.05.025

4. Testa S, Tripodi A, Legnani C, Pengo V, Abbate R, Dellanoce C, Carraro P, Salomone L, Paniccia R, Paoletti O, Poli D, Palareti G, START-Laboratory Register (2016) Plasma levels of direct oral anticoagulants in real life patients with atrial fibrillation: results observed in four anticoagulation clinics. Thromb Res 137:178-183

5. Rottenstreich A, Zacks N, Kleinstern G, Raccah BH, Roth B, Da' as N, Kalish Y (2018) Direct-acting oral anticoagulant drug level monitoring in clinical patient management. J Thromb Thrombol 45:543-549. https://doi.org/10.1007/s11239-018-1643-0

6. Martin K, Beyer-Westendorf J, Davidson BL, Huisman MV, Sandset PM, Moll S (2016) Use of the direct oral anticoagulants in obese patients: guidance from the SSC of the ISTH. J Thromb Haemost 14:1308-1313. https://doi.org/10.1111/jth.13323

7. Moll S, Martin KA (2018) Anticoagulant drug choice in patients who have had bariatric surgery-presently, DOACs are not the preferred choice. Thromb Res 163:196-199

8. Herink MC, Zhuo YF, Williams CD, DeLoughery TG (2019) Clinical management of pharmacokinetic drug interactions with direct oral anticoagulants (DOACs). Drugs 79:1625-1634. https ://doi.org/10.1007/s40265-019-01183-0

9. Rottenstreich A, Barkai A, Arad A, Raccah BH, Kalish Y (2018) The effect of bariatric surgery on direct-acting oral anticoagulant drug levels. Thromb Res 163:190-195

10. Kroll D, Stirnimann G, Vogt A, Lai DLL, Borbely YM, Altmeier J, Schadelin S, Candinas D, Alberio L, Nett PC (2017) Pharmacokinetics and pharmacodynamics of single doses of rivaroxaban in obese patients prior to and after bariatric surgery. Br J Clin Pharmacol 83:1466-1475. https://doi.org/10.1111/bcp.13243

11. Testa S, Legnani C, Antonucci E, Paoletti O, Dellanoce C, Cosmi B, Pengo V, Poli D, Morandini R, Testa R, Tripodi A, Palareti G, Coordinator of START2-Register (2019) Drug levels and bleeding complications in atrial fibrillation patients treated with direct oral anticoagulants. J Thromb Haemost 17:1064-1072. https:// doi.org/10.1111/jth.14457

12. Ruff CT, Giugliano RP, Braunwald E, Morrow DA, Murphy SA, Kuder JF, Deenadayalu N, Jarolim P, Betcher J, Shi M, Brown K, Patel I, Mercuri M, Antman EM (2015) Association between edoxaban dose, concentration, anti-Factor Xa activity, and outcomes: an analysis of data from the randomised, double-blind ENGAGE AF-TIMI 48 trial. Lancet 385:2288-2295. https://doi. org/10.1016/S0140-6736(14)61943-7

13. Bohula EA, Giugliano RP, Ruff CT, Kuder JF, Murphy SA, Antman EM, Braunwald E (2016) Impact of renal function on outcomes with edoxaban in the ENGAGE AF-TIMI 48 trial. Circulation 134:24-36. https://doi.org/10.1161/CIRCULATIO NAHA.116.022361

14. Reilly PA, Lehr T, Haertter S, Connolly SJ, Yusuf S, Eikelboom JW, Ezekowitz MD, Nehmiz G, Wang S, Wallentin L, Investigators RE-LY (2014) The effect of dabigatran plasma concentrations and patient characteristics on the frequency of ischemic stroke and major bleeding in atrial fibrillation patients: the RE-LY Trial (randomized evaluation of long-term anticoagulation therapy). J Am Coll Cardiol 63:321-328. https://doi.org/10.1016/j. jacc.2013.07.104

15. Bhagirath VC, Eikelboom JW, Hirsh J, Coppens M, Ginsberg J, Vanassche T, Yuan F, Chan N, Yusuf S, Connolly SJ (2017) Apixaban-calibrated Anti-FXa activity in relation to outcome events and clinical characteristics in patients with atrial fibrillation: results from the AVERROES trial. TH Open 1:e139-e145. https://doi.org/10.1055/s-0037-1613679

16. Wada S, Toyoda K, Sato S, Matsuki T, Okata T, Kumamoto M, Tagawa N, Inoue M, Okamoto A, Ihara M, Kitazono T, Miyata T, Koga M (2018) Anti-Xa activity and event risk in patients with direct factor Xa inhibitors initiated early after stroke. Circ J 82:2872-2879. https://doi.org/10.1253/circj.CJ-18-0506

17. Krause M, Henningsen A, Torge A, Juhl D, Junker R, Kenet G, Kowalski D, Limperger V, Mesters R, Anonymous RA, Shneyder M, Clausnizer H, Schiesewitz H, Nowak-Gottl U (2016) Impact of gender on safety and efficacy of Rivaroxaban in adolescents $\&$ young adults with venous thromboembolism. Thromb Res 148:145-151

18. Solms A, Frede M, Berkowitz SD, Hermanowski-Vosatka A, Kubitza D, Mueck W, Spiro TE, Willmann S, Yan X, Zhang L, Garmann D (2019) Enhancing the quality of rivaroxaban exposure estimates using prothrombin time in the absence of pharmacokinetic sampling. CPT Pharmacometr Syst Pharmacol 8:805-814. https://doi.org/10.1002/psp4.12444

19. Leil TA, Frost C, Wang X, Pfister M, LaCreta F (2014) Modelbased exposure-response analysis of apixaban to quantify bleeding risk in special populations of subjects undergoing orthopedic surgery. CPT Pharmacometr Syst Pharmacol 3:e136. https://doi. org/10.1038/psp.2014.34

20. Zeitouni M, Giczewska A, Lopes RD, Wojdyla DM, Christersson C, Siegbahn A, De Caterina R, Steg PG, Granger CB, Wallentin L, Alexander JH, Investigators ARISTOTLE (2020) Clinical and pharmacological effects of apixaban dose adjustment in the ARISTOTLE trial. J Am Coll Cardiol 75:1145-1155

21. Hohnloser SH, Hijazi Z, Thomas L, Alexander JH, Amerena J, Hanna M, Keltai M, Lanas F, Lopes RD, Lopez-Sendon J, Granger CB, Wallentin L (2012) Efficacy of apixaban when compared with warfarin in relation to renal function in patients with atrial fibrillation: insights from the ARISTOTLE trial. Eur Heart J 33:2821-2830. https://doi.org/10.1093/eurheartj/ehs274

22. Gosselin RC, Adcock DM, Bates SM, Douxfils J, Favaloro EJ, Gouin-Thibault I, Guillermo C, Kawai Y, Lindhoff-Last E, Kitchen S (2018) International council for standardization in haematology (ICSH) recommendations for laboratory measurement of direct oral anticoagulants. Thromb Haemost 118:437-450. https://doi.org/10.1055/s-0038-1627480

Publisher's Note Springer Nature remains neutral with regard to jurisdictional claims in published maps and institutional affiliations. 